\title{
Editorial
}

Nephrology

\section{Aldosterone: The Missing Cardiorenal Link}

\author{
Gordon H. Williams \\ Brigham and Women's Hospital, Harvard Medical School, Boston, MA, USA
}

Classically, the renin-angiotensin-aldosterone system (RAAS) primarily is a critical factor that allows an organism to maintain normal volume homeostasis in the face of changing environmental circumstances. Evolutionarily, the RAAS has evolved primarily to protect against volume depletion such as would occur if the organism was exposed to a hot environment, trauma with blood loss, salt and volume depletion, and/or salt or volume losing illnesses, for example, diarrhea. While an activated RAAS is still critical today to meet these challenges, during the past 60 years, increasingly important are the conditions where activation of this system is harmful to the individual. An extensive body of both preclinical and clinical literature have documented that inhibiting the RAAS is important in reducing end-organ damage in a variety of cardiovascular/renal diseases. However, implementing this knowledge into clinical practice has been slow and spotty.

\section{Renin-Angiotensin System and Renal Disease}

Preclinical data from the early 1960s have supported the hypothesis that activation of the renin-angiotensin system can be harmful to the kidney if it is diseased or dysfunctional. Application of this hypothesis to humans occurred in the 1970s when E.R. Squibb and Sons Pharmaceuticals developed a new class of agents, angiotensinconverting enzyme (ACE) inhibitors, based on the work of Vance and the composition of venom from a Brazilian pit viper Bothrops jararaca [1,2]. Within a few short years, several drugs from this class of agents were introduced to treat a variety of conditions including hypertension and

\section{KARGER}

() 2019 S. Karger AG, Basel

E-Mail karger@karger.com

www.karger.com/ajn renal artery stenosis, but not chronic renal failure [3]. Indeed, during much of the 1980s because of the increased risk of renal failure and/or hyperkalemia, ACE inhibitors were contraindicated in individuals with chronic renal failure [4-6]. However, several preclinical studies and some small human observational studies suggested that if administered carefully, ACE inhibitors could improve renal function and preserved renal tissue, but there were no clinical trial data to support this claim. In 1993, Lewis et al. [7] provided such data. In a randomized clinical trial, they documented in type I diabetics with protein excretion $>$ $500 \mathrm{mg} /$ day and serum creatinine $<2.5 \mathrm{mg} / \mathrm{dL}$ that the addition of the ACE inhibitor captopril to standard therapy significantly ( $p=0.007)$ reduced the number of subjects who doubled their serum creatinine during the trial. Further, they documented that the combined endpoint of progression to dialysis, transplantation, and renal death was reduced in half. Since during the trial, blood pressure (BP) and glucose levels were equally well controlled in both arms of the study, the authors concluded that "captopril protects against deterioration in renal function in insulin-dependent diabetic nephropathy and is significantly more effective than blood-pressure control alone [7]."

\section{Aldosterone and Mineralocorticoid Receptor Blockade}

Four years after Simpson et al. [8] reported the discovery of aldosterone in 1953, Searle reported the development of an antagonist to aldosterone (spironolactone) [9]. 
It was introduced into clinical practice in 1959. Later, it was determined that spironolactone competitively inhibited the binding of aldosterone to the mineralocorticoid receptor (MR). Because of aldosterone's effect on sodium retention and volume expansion and its association with adrenal tumors in patients with hypertension, the initial use of spironolactone was in patients with edema disorders and hypertension [9]. Because thiazide diuretics were also used in these disorders, spironolactone became known as a potassium-sparing diuretic in contrast to the frequent association of hypokalemia with thiazide treatment. Often combination treatment was given to "balance" the effect of the 2 classes of agents on potassium homeostasis. However, with the development of more potent diuretics, the use of amiloride as another potassium sparing agent and the belief that ACE inhibitors and angiotensin receptor blockers (ARB) effectively removed aldosterone as a cardiovascular risk factor, and the need for and use of spironolactone diminished substantially during the 1980s and 1990s [9]. Then, over the past 25 years, several events have refocused our attention on the potential adverse effects of aldosterone in cardiovascular and renal diseases and the beneficial effects of MR antagonists (MRAs).

\section{Aldosterone's Mechanism of Action}

During the first 4 decades following the discovery of aldosterone, studies of its renal (epithelial) effects were the focus of mechanistic studies [9]. However, in the past 2 decades, an expansion of our understanding of aldosterone's mechanism of action has occurred, specifically in 2 areas - cells targeted and pathways used. Classically, it has been known that aldosterone (through its interaction with the MR) modulates the function of epithelial (particularly renal) cells, thereby modifying sodium absorption to assist in the maintenance of appropriate volume homeostasis [9]. Now we know that some of aldosterone's effects may likely be mediated by activation of the MR on nonepithelial cells, for example, cardiac, smooth muscle, adrenal, endothelial, and immune [9]. In addition, data have accumulated suggesting that when aldosterone binds to the $\mathrm{MR}$, not 1 but 2 pathways are activated: the genomic pathway, where aldosterone/MR acts as a nuclear transcription factor, and the rapidly activated, nongenomic pathway [10-12]. Activation of the nongenomic pathway increases phosphorylation of several proteins, including those in the mitogen-activated protein kinase pathway [10].

Among the established experimental models of cardiovascular and renal damage, 2 , involving MR activa- tion, are illustrative of approaches that likely are associated with activation of MR on the contrasting cell types noted above - exogenously administered aldosterone and NG-nitro-L-arginine methyl ester (L-NAME)-induced deficiency of nitric oxide $[13,14]$. Both require liberal sodium consumption. Injury in both models is MR mediated as treatment with an MRA prevents or ameliorates the damage. While BP is increased in both models, hypertension does not appear to be a critical mediator of the damage, as an MRA reduces the damage without having much, if any, effect on the BP at least in the L-NAME model [13]. Yet the aldosterone levels are different - high in the exogenous aldosterone model and low in the LNAME model. The damage in the former model is presumed to be secondary to volume expansion via activation of MR on epithelial cells. The damage in the L-NAME model may largely be secondary to activation of MR on nonepithelial cells. However, whether the damage in either model is mediated by MR's genomic and/or nongenomic pathways is unknown.

\section{Aldosterone, MR Blockade, and Cardiovascular Disease}

The second major event that has occurred is the documentation that ACE inhibition does not remove aldosterone as a cardiovascular risk factor. When patients were treated with ACE inhibitors or ARB, the assumption was that aldosterone production would be reduced and thereby aldosterone's adverse cardiovascular effects would be substantially reduced or eliminated. However, several studies have documented that suppression of aldosterone levels does not persist with long-term treatment with ACE inhibitors whether the patient had hypertension or heart failure [9]. Furthermore, treatment with an MRA on top of an ACE inhibitor further reduced cardiovascular damage in patients with left ventricular hypertrophy and hypertension [15], death and hospitalization in patients with congestive heart failure (CHF) whether chronic [16] or acute post myocardial infarction [17]. In each study, there was little or no evidence that the beneficial effects were secondary to differences in BP or volume status between the treated and control groups, suggesting that the beneficial effects may be mediated via blockade of the MR on nonepithelial cells. Intriguingly in the CHF studies, only low MRA doses were used to produce these beneficial effects. Several preclinical studies have supported the conclusions from these clinical trials, as noted above $[13,14]$. 


\section{Development of New MRAs}

The third major event that has refocused clinical and research activities on aldosterone's role in health and disease has been the development of new MRAs designed to overcome some of spironolactone's deficiencies. While spironolactone is an effective MRA, it also has significant side effects that limit its usefulness in treating chronic diseases, namely, it can modify the activity of the progesterone and androgen receptors at clinically useful doses, and it can induce hyperkalemia in renally compromised patients. While spironolactone and its active metabolite have long half-lives, this characteristic is a 2-edge sword: good for therapeutic benefit, bad for prolonging adverse effects. The first biochemical approach to addressing these issues used a steroid nucleus base as its structure. The product, eplerenone, was introduced in 2002. Its advantages over spironolactone were its substantially reduced interaction with the androgen and progesterone receptors and a lower frequency of hyperkalemia than spironolactone [18]. However, it is also less potent than spironolactone.

A second approach to overcome the deficiencies of spironolactone-mediated therapy has been to develop a nonsteroid-based backbone to block the MR. Several such agents are under development, for example, apararenone, esaxerenone, and finerenone [19-21]. Esaxerenone has been approved in Japan for the treatment of hypertension. To date, all have been shown to be more potent than spironolactone and eplerenone and have no sexual side effects. While some data suggest that they may have smaller potassium retention effects, long-term studies have not been reported.

\section{Aldosterone and Renal Disease}

Like the renin-angiotensin system, the role of aldosterone in initiating and/or accelerating renal disease has been checkered. In the 1970s with documentation of increased aldosterone levels and its associated effects (ede$\mathrm{ma}$ ) in chronic renal failure [22, 23], spironolactone was used to treat the edema associated with renal disease. However, with increasing spironolactone use, reports of hyperkalemia became common and even an occasional death occurred [24]. Thus, despite the clinical and experimental data suggesting that aldosterone was a substantial risk factor in chronic renal disease, enthusiasm was dampened for blocking the MR. Renewed interest in assessing the role of MRAs in chronic kidney disease occurred after the positive results from the CHF trials (as noted above) were reported, specifically because of the common occurrence of chronic kidney disease and CHF. In a recent review, the authors concluded: "...data from research with surrogate end points suggest that spironolactone-mediated inhibition of the RAAS provides beneficial results at structural and physiological levels in heart failure patients with CKD patients" [25].

Furthermore, in patients with diabetes mellitus and renal damage treated with an ARB or ACE inhibitor, adding an MRA for 3-6 months produces a substantially further reduction in albuminuria. The reductions in albumin excretion were seen even though there were little or no changes in BP. Of interest, usually the near-maximum reduction in albuminuria occurs with an MRA dose that had minimal, if any, effect on the development of hyperkalemia [26]. Thus, the beneficial effects of MRAs in chronic renal disease may also be mediated by blocking the MR on nonepithelial cells like what appears to be correct in $\mathrm{CHF}$.

\section{Summary}

New MRAs have been developed because of spironolactone's side effects, specifically hyperkalemia and changes in sex hormone functions and/or levels. As stated earlier, eplerenone has minimal sexual side effects and lower frequency of hyperkalemia than spironolactone. Yet, the FDA-approved label states that eplerenone is contraindicated in "all patients with serum creatinine clearance $\leq 30 \mathrm{~mL} / \mathrm{min} . .$. and for the treatment of hypertension in patients with type 2 diabetes with microalbuminuria or serum creatinine $>2.0 \mathrm{mg} / \mathrm{dL}$ in males or $>1.8 \mathrm{mg} / \mathrm{dL}$ in females." Thus, like the early use of ACE inhibitors in the very condition in which an MRA may be particularly beneficial, it is contraindicated.

To restore balance to the use of MRAs in chronic kidney disease, an approach like what Lewis et al. [7] did for ACE inhibitors is required: a large-scale, randomized, well-designed clinical trial in the appropriate patient population. The dual studies of finerenone in diabetic kidney disease as described in this issue of the American Journal of Nephrology are examples of such needed trials $[27,28]$. In FIGARO-DKD, cardiovascular morbidity and mortality will be assessed with kidney disease progression as a prespecified secondary end point, while in FIDELIO$\mathrm{DKD}$, progression of kidney disease will be determined and cardiovascular outcomes as a pre-specified secondary end point. Both are event-driven trials with $>13,000$ participants combined. The outcome from these trials should 
provide critical data to determine the role of MRAs in the treatment of patients with chronic kidney disease as RALES and EPHESUS did for chronic heart failure.

\section{Acknowledgments}

Dr. Gordon H. Williams has no conflict of interests to report or financial support related to this manuscript.

\section{References}

1 Ondetti MA, Rubin B, Cushman DW. Design of specific inhibitors of angiotensinconverting enzyme: new class of orally active antihypertensive agents. Science. 1977 Apr; 196(4288):441-4.

2 Vane JR. The history of inhibitors of angiotensin converting enzyme. J Physiol Pharmacol. 1999 Dec;50(4):489-98.

3 Brunner HR, Gavras H, Waeber B, Kershaw GR, Turini GA, Vukovich RA, et al. Oral angiotensin-converting enzyme inhibitor in long-term treatment of hypertensive patients. Ann Intern Med. 1979 Jan;90(1):19-23.

4 Collste P, Haglund K, Lundgren G, Magnusson G, Ostman J. Reversible renal failure during treatment with captopril. BMJ. 1979 Sep; 2(6190):612-3.

5 Textor SC, Bravo EL, Fouad FM, Tarazi RC. Hyperkalemia in azotemic patients during angiotensin-converting enzyme inhibition and aldosterone reduction with captopril. Am J Med. 1982 Nov;73(5):719-25.

6 Grossman A, Eckland D, Price P, Edwards CR. Captopril: reversible renal failure with severe hyperkalaemia. Lancet. 1980 Mar;1(8170): 712.

7 Lewis EJ, Hunsicker LG, Bain RP, Rohde RD; The Collaborative Study Group. The effect of angiotensin-converting-enzyme inhibition on diabetic nephropathy. N Engl J Med. 1993 Nov;329(20):1456-62.

8 Simpson SA, Tait JF, Wettstein A, Neher R, Von Euw J, Reichstein T. Isolierung eines neuen kristallisierten Hormons aus Nebennieren mit besonders hoher Wirksamkeit auf den Mineralstoffwechsel. Experientia. 1953 Sep;9(9):333-5.

9 Williams JS, Williams GH. 50th Anniversary of Aldosterone. J Clin Endocrinol Metab. 2003;88(6):2364-72.

10 Baudrand R, Pojoga LH, Romero JR, Williams GH. Aldosterone's mechanism of action: roles of lysine-specific demethylase 1, caveolin and striatin. Curr Opin Nephrol Hypertens. 2014 Jan;23(1):32-7.

11 Fuller PJ, Young MJ. Mechanisms of mineralocorticoid action. Hypertension. 2005 Dec; 46(6):1227-35.
12 Díez J. Effects of aldosterone on the heart: beyond systemic hemodynamics? Hypertension. 2008 Sep;52(3):462-4.

13 Rocha R, Stier CT Jr, Kifor I, Ochoa-Maya MR, Rennke HG, Williams GH, et al. Aldosterone: a mediator of myocardial necrosis and renal arteriopathy. Endocrinology. 2000 Oct; 141(10):3871-8.

14 Brooks DL, Garza AE, Katayama IA, Romero JR, Adler GK, Pojoga LH, et al. Aldosterone Modulates the Mechanistic Target of Rapamycin Signaling in Male Mice. Endocrinology. 2019 Apr;160(4):716-28.

15 Pitt B, Reichek N, Willenbrock R, Zannad F, Phillips RA, Roniker B, et al. Effects of eplerenone, enalapril, and eplerenone/enalapril in patients with essential hypertension and left ventricular hypertrophy: the 4E-left ventricular hypertrophy study. Circulation. 2003 Oct; 108(15):1831-8.

16 Pitt B, Zannad F, Remme WJ, Cody R, Castaigne A, Perez A, et al.; Randomized Aldactone Evaluation Study Investigators. The effect of spironolactone on morbidity and mortality in patients with severe heart failure. N Engl J Med. 1999 Sep;341(10):70917.

17 Pitt B, Remme W, Zannad F, Neaton J, Martinez F, Roniker B, et al.; Eplerenone PostAcute Myocardial Infarction Heart Failure Efficacy and Survival Study Investigators. Eplerenone, a selective aldosterone blocker, in patients with left ventricular dysfunction after myocardial infarction. N Engl J Med. 2003 Apr;348(14):1309-21.

18 Ménard J. The 45-year story of the development of an anti-aldosterone more specific than spironolactone. Mol Cell Endocrinol. 2004 Mar;217(1-2):45-52.

19 Arai K, Homma T, Morikawa Y, Ubukata N, Tsuruoka H, Aoki K, et al. Pharmacological profile of CS-3150, a novel, highly potent and selective non-steroidal mineralocorticoid receptor antagonist. Eur J Pharmacol. 2015 Aug;761:226-34.

20 Bakris GL, Agarwal R, Chan JC, Cooper ME, Gansevoort RT, Haller H, et al.; Mineralocorticoid Receptor Antagonist Tolerability
Study-Diabetic Nephropathy (ARTS-DN) Study Group. Effect of Finerenone on Albuminuria in Patients With Diabetic Nephropathy: A Randomized Clinical Trial. JAMA. 2015 Sep;314(9):884-94.

21 Kolkhof P, Bärfacker L. 30 Years of the mineralocorticoid receptor: Mineralocorticoid receptor antagonists: 60 years of research and development. J Endocrinol. 2017 Jul;234(1): T125-40.

22 Manning RT, Behrle FC. Use of spironolactone in renal edema. Effectiveness and association with hyperkalemia. JAMA. 1961 Jun; 176(9):769-71.

23 Berl T, Katz FH, Henrich WL, de Torrente A, Schrier RW. Role of aldosterone in the control of sodium excretion in patients with advanced chronic renal failure. Kidney Int. 1978 Sep;14(3):228-35.

24 Sjoberg WE Jr, Kreisle JE. Hyperkalemia and sudden death during Spironolactone (Aldactone) therapy. Tex State J Med. 1962 Dec;58: 1022-4.

25 Agrawal S, Agrawal N, Garg J, Mohandas R, Gupta T, Segal M. Heart failure and chronic kidney disease: should we use spironolactone? Am J Med Sci. 2015 Aug;350(2):14751.

26 Epstein M, Williams GH, Weinberger M, Lewin A, Krause S, Mukherjee R, et al. Selective aldosterone blockade with eplerenone reduces albuminuria in patients with type 2 diabetes. Clin J Am Soc Nephrol. 2006 Sep; 1(5): 940-51.

27 Ruilope LM, Agarwal R, Anker SD, Bakris GL, Filippatos G, Nowack C, et al.; on behalf of the FIDELIO-DKD study investigators. Design and baseline characteristics of the finerenone in reducing cardiovascular mortality and morbidity in diabetic kidney disease trial. Am J Nephrol. 2019, DOI: 10.1159/000503712.

28 Bakris GL, Agarwal R, Anker SD, Pitt B, Ruilope LM, Nowack C, et al.; on behalf of the FIDELIO-DKD study investigators. Design and baseline characteristics of the finerenone in reducing kidney failure and disease progression in diabetic kidney disease trial. Am J Nephrol. 2019, DOI: 10.1159/000503713. 